\title{
ANALISIS PENDAPATAN DAN TINGKAT KESEJAHTERAAN RUMAH TANGGA PETANI SAYURAN DI KECAMATAN GISTING KABUPATEN TANGGAMUS
}

\author{
(Income and Welfare Level Analysis of Vegetable Farmer Households in Gisting Subdistrict \\ Tanggamus Regency)
}

Synthia Ayu Disha, Dwi Haryono, Ani Suryani

Jurusan Agribisnis, Fakultas Pertanian, Universitas Lampung, Jl. Prof. Dr. Soemantri Brodjonegoro No. 1

Bandar Lampung 35145, e-mail: dwi.haryono@fp.unila.ac.id

\begin{abstract}
This study aims to analyze farming income, household income, and welfare level of vegetable farmer households. This research was conducted in Gisting Subdistrict, Tanggamus Regency. This research was conducted in Januari 2017 until Januari 2018 using a survey method. The results showed that cropping patern A consisted of mustard greens-chili-tomato-bean (planting season I), cabbage (planting season II), whereas, cropping patern B consisted of mustard greens-chili-tomato (planting season I), cabbage (planting season II). Both patterns were advantageous to cultivate $(R / C>1)$. The income of farmer households from on farm activities gives the highest contribution. Household income received by farmers from cropping pattern A was IDR71,410,517.81/year while cropping pattern B was IDR49,781,431.68/year. Based on the criteria of the Central Bureau of Statistics (2014), there were $82.35 \%$ of vegetable farmer households in Gisting Subdistrict, Tanggamus Regency which belonged to welfare households.
\end{abstract}

Key words: farmer, income, level of welfare, vegetable

\section{PENDAHULUAN}

Sektor pertanian sebagai sektor primer memberikan kontribusi terhadap pertumbuhan ekonomi dan kesejahteraan di Indonesia. Pertanian terbagi ke dalam beberapa subsektor. Salah satu subsektor yang memberikan peranan penting bagi perekonomian adalah subsektor hortikultura. Salah satu tanaman hortikultura yang dapat dikembangkan yaitu tanaman sayuran. Terdapat beberapa jenis tanaman sayuran yang banyak dikembangkan di Indonesia, diantaranya adalah bawang merah, kentang, terung, tomat, dan kubis (Direktorat Jenderal Hortikultura 2015).

Kabupaten Tanggamus merupakan daerah yang memiliki potensi dalam pengembangan usahatani sayuran di Provinsi Lampung. Kabupaten Tanggamus merupakan kabupaten yang memiliki potensi besar di bidang pertanian. Kondisi agroklimat yang baik serta ketersediaan sumberdaya sangat mendukung tumbuh kembangnya tanaman hortikultura. Tanaman sayuran di Kecamatan Gisting memiliki tanaman sawi dengan luas panen 17,00 ha, produksi 136,00 ton, dan produktivitas $80,00 \mathrm{ku} / \mathrm{ha}$, tanaman cabai memiliki luas panen 8,00 ha, produksi 136,00 ton, dan produktivitas $170,00 \mathrm{ku} / \mathrm{ha}$, tanaman tomat memiliki luas panen 15,00 ha, produksi 150,00 ton, dan produktivitas $100,00 \mathrm{ku} / \mathrm{ha}$, tanaman buncis memiliki luas panen 10,00 ha, produksi 100,00 ton, dan produktivitas $100,00 \mathrm{ku} / \mathrm{ha}$, sedangkan tanaman kubis memiliki luas panen 16,00 ha, produksi 448,00 ton, dan produktivitas 280,00 ku/ha (Dinas Pertanian Tanaman Pangan dan Hortikultura Kabupaten Tanggamus 2017). Oleh karena itu, tanaman sayuran menjadi salah satu sektor usaha yang berpotensi dikembangkan untuk meningkatkan pendapatan masyarakat.

Kegiatan pertanian di Kecamatan Gisting dapat didukung oleh berbagai aspek yaitu aspek sumberdaya alam dan aspek sarana dan prasarana yang terdapat di kecamatan tersebut. Dalam pengamatan pendahuluan yang dilakukan, berbagai sarana dan prasarana yang tersedia dapat menyokong petani dalam melancarkan kegiatan usahatani mulai dari input sampai pada kegiatan pemasaran. Salah satunya dalam kegiatan pemasaran, petani menceritakan harga yang diterima petani pada komoditas cabai sebesar Rp17.000,00 per kg. Oleh karena tingginya harga sayuran yang diterima petani menyebabkan semakin tinggi penerimaan yang diterima petani sayuran. Akan tetapi, banyak petani yang mencari pekerjaan lain di luar sektor pertanian seperti buruh, tukang ojek, berdagang dan lain sebagainya untuk memenuhi kebutuhan rumah tangga. Hal ini tentu berkaitan dengan tingkat kesejahteraan petani sayuran di Kecamatan Gisting sebagai sentra 
penghasil sayuran di Kabupaten Tanggamus. Tingkat kesejahteraan masyarakat secara umum dapat ditunjukkan oleh meningkatnya pendapatan per kapita suatu wilayah. Semakin tinggi tingkat perolehan pendapatan per kapita menunjukkan semakin tinggi pula tingkat kesejahteraannya. Sebaliknya, penurunan pada tingkat pendapatan per kapita menunjukkan tingkat kesejahteraan yang semakin menurun (Badan Pusat Statistik 2017).

Berdasarkan Dinas Pengendalian Penduduk dan Keluarga Berencana (2017), Kecamatan Gisting memiliki jumlah keluarga sejahtera sebanyak 7.784 keluarga. Hal ini menggambarkan bahwa mayoritas masyarakat di Kecamatan Gisting yang bekerja sebagai petani dikatakan sejahtera. Penelitian ini bertujuan untuk menganalisis tingkat pendapatan usahatani sayuran, besarnya pendapatan rumah tangga petani sayuran, dan tingkat kesejahteraan rumah tangga petani sayuran di Kecamatan Gisting, Kabupaten Tanggamus.

\section{METODE PENELITIAN}

Pengambilan data dilakukan pada bulan JanuariApril 2018 menggunakan metode survei. Lokasi penelitian berada di Kecamatan Gisting yang merupakan sentra produksi sayuran. Pekon yang dipilih menjadi alokasi penelitian yaitu Pekon Gisting Atas dan Pekon Gisting Permai dengan pertimbangan bahwa kedua pekon merupakan sentra produksi sayuran di Kecamatan Gisting.

Populasi petani sayuran di Pekon Gisting Atas dan Pekon Gisting Permai yaitu sebanyak 409 dan 331 petani sayuran. Berdasarkan jumlah populasi petani responden tersebut, ditemukan jumlah sampel dengan menggunakan rumus yang merujuk pada teori Sugiarto, Siagian, Sunaryanto, dan Oetomo (2003) yaitu:

$\mathrm{n}=\frac{\mathrm{NZ}^{2} \mathrm{~S}^{2}}{\mathrm{ND}^{2}+\mathrm{Z}^{2} \mathrm{~S}^{2}}$

Keterangan:

$\mathrm{n}$ = Jumlah sampel

$\mathrm{N}$ = Jumlah populasi (740)

$\mathrm{Z}=$ Distribusi $\mathrm{Z}$ dari unit populasi $(90 \%=1,645)$

$S^{2}=$ Tingkat kepercayaan $(5 \%=0,05)$

$\mathrm{D}=$ Simpangan baku $(5 \%=0,05)$

Dengan perhitungan:

$\begin{aligned} \mathrm{n} & =\frac{740(1,645)^{2}(0,05)}{740(0,05)^{2}+(1,645)^{2}(0,05)} \\ & =51\end{aligned}$
Berdasarkan perhitungan dengan menggunakan rumus, diperoleh jumlah sampel sebanyak 51 petani di Kecamatan Gisting Kabupaten Tanggamus.

Metode analisis data yang digunakan dalam penelitian ini adalah analisis kuantitatif dan kualitatif. Analisis kuantitatif digunakan untuk mengetahui besarnya pendapatan rumah tangga petani sayuran, sedangkan analisis deskriptif kualitatif digunakan untuk menggambarkan objek penelitian pada saat sekarang, yaitu tingkat kesejahteraan rumah tangga petani sayuran di Kecamatan Gisting Kabupaten Tanggamus. Metode pengolahan data dilakukan dengan menggunakan metode tabulasi dan komputasi.

Pendapatan usahatani diperoleh dengan menghitung selisih antara penerimaan yang diterima dari hasil usahatani dengan biaya produksi yang dikeluarkan dalam satu tahun. Untuk mengetahui pendapatan usahatani digunakan rumus Soekartawi (1995):

$\pi=\mathrm{TR}-\mathrm{TC}$ $\pi=$

(Y.Py) - $\sum$ XiPxi-BTT

$\mathrm{R} / \mathrm{C}=\frac{\mathrm{TR}}{\mathrm{TC}}$.

Keterangan:

$\pi \quad=$ Pendapatan usahatani

$\mathrm{TR}=$ Penerimaan usahatani

$\mathrm{TC}=$ Biaya usahatani

$\mathrm{Y}=$ Output atau produksi yang diperoleh

Py = Price atau harga output

$\mathrm{BTT}=$ Biaya tetap total usahatani

$\mathrm{R} / \mathrm{C}=$ Nisbah antara penerimaan dengan biaya

Kriteria pengukuran pada R/C (Return Cost Ratio) adalah:

a. jika $\mathrm{R} / \mathrm{C}>1$, artinya usahatani yang dilakukan menguntungkan,

b. jika $\mathrm{R} / \mathrm{C}=1$, artinya usahatani yang dilakukan berada pada titik impas (break event point),

c. jika $\mathrm{R} / \mathrm{C}<1$, artinya usahatani yang dilakukan merugikan.

Prt = $\mathrm{P}$ on farm utama $+\mathrm{P}$ on farm bukan utama $+\mathrm{P}$ off farm $+\mathrm{P}$ non farm.

Keterangan:

Prt

$=$ Pendapatan rumah tangga (Rp)

Pon farm utama =Pendapatan dari usahatani sayuran (Rp) 


$\begin{array}{ll}\text { Pon farm bukan utama = } & \text { Pendapatan dari } \\ & \text { usahatani bukan sayuran } \\ & (\mathrm{Rp}) \\ = & \text { Pendapatan dari } \\ & \text { usahatani di luar sayuran } \\ & (\mathrm{Rp}) \\ \text { Poff farm } & \text { Pendapatan di luar } \\ & \text { pertanian }(\mathrm{Rp})\end{array}$

Untuk mengetahui kontribusi pendapatan yang diperoleh dari usahatani sayuran terhadap pendapatan total rumah tangga dihitung dengan rumus Hastuti dan Rahim (2008):

$\mathrm{pPs}=(\mathrm{Ps} / \mathrm{Prt}) \times 100 \%$

Keterangan:

pPs $=$ Persentase pendapatan usahatani sayuran

Ps = Pendapatan usahatani sayuran

Prt = Pendapatan total rumah tangga per tahun

Alat analisis yang digunakan yaitu indikator Bank Dunia dan Badan Pusat Statistik (2014). Bank Dunia menetapkan garis kemiskinan internasional yang dinyatakan dalam suatu mata uang tunggal (Common Currency), yakni dollar Amerika Serikat. Dollar Amerika Serikat dipilih sebagai acuan (banchmark), karena mata uang ini dapat diterima oleh hampir semua negara. Bank Dunia menetapkan garis kemiskinan internasional sebesar 1 dollar Amerika Serikat per kapita per hari. Selain indikator Bank Dunia, tingkat kesejahteraan petani sayuran juga diukur menggunakan tujuh indikator Badan Pusat Statistik (2014) yang meliputi kependudukan, kesehatan dan gizi, pendidikan, ketenagakerjaan, taraf dan pola konsumsi, perumahan dan lingkungan, sosial dan lain-lain.

\section{HASIL DAN PEMBAHASAN}

\section{Karakteristik Responden}

Berdasarkan hasil penelitian diketahui bahwa, sebanyak 100,00 persen petani berusia antara 26 sampai 57 tahun, yang berarti bahwa petani berada pada usia kerja (Badan Pusat Statistik 2018). Namun, untuk tingkat pendidikan petani masih tergolong rendah, hal ini dikarenakan sebanyak 39,22 persen petani yang menyelesaikan pendidikan sampai Sekolah Menengah Atas (SMA). Petani yang berpendidikan tinggi akan lebih cepat dalam mengadopsi inovasi dan teknologi usahatani terbaru dibandingkan dengan petani yang berpendidikan lebih rendah (Soekartawi 2002). Jumlah tanggungan keluarga petani berkisar antara tiga sampai enam orang, dimana 66,77 persen petani memiliki tanggungan keluarga sebanyak 4-6 orang.

\section{Analisis Pendapatan Rumah Tangga Petani}

Petani di daerah penelitian umumnya menanam sayuran sebagai komoditas utama. Terdapat beberapa pola tanam yang dilakukan oleh petani. Namun, terdapat dua pola tanam yang mayoritas dilakukan oleh petani. Pola tanam tersebut adalah pola tanam A sawi-cabai-tomat-buncis pada musim tanam I (Januari sampai Juli) dan kubis pada musim tanam II (Agustus sampai Desember). Pola tanam B sawi-cabai-tomat pada musim tanam I (Januari sampai Juli) dan kubis pada musim tanam II (Agustus sampai Desember).

a. Pola tanam A sawi-cabai-tomat-buncis (musim tanam I) dan kubis (musim tanam II)

Benih yang digunakan petani sesuai dengan pengalaman berusahatani. Harga benih yang dibeli petani dari kios pertanian relatif sama, karena petani responden membeli benih di tempat yang sama yang ada di Kecamatan Gisting.

Jenis pupuk kimia yang sering digunakan oleh petani di lokasi penelitian adalah pupuk ZA, urea, NPK phonska, TSP, $\mathrm{KCl}$, dan NPK mutiara. Penggunaan pupuk kimia tidak sesuai anjuran yang ditetapkan oleh Pusat Penelitian dan Pengembangan Hortikultura (2017), karena penggunaan pupuk lebih sedikit dibandingkan anjuran yang telah ditetapkan. Penggunaan ratarata pupuk kandang masih sedikit yaitu $2.726,19$ $\mathrm{kg} / \mathrm{ha} /$ musim tanam di bawah standar dosis dari Pusat Penelitian dan Pengembangan Hortikultura yaitu sebesar $30.000,00 \mathrm{~kg} / \mathrm{ha}$.

Total biaya yang dikeluarkan untuk pupuk pada tanaman sayuran pola tanam A sawi-cabai-tomatbuncis (musim tanam I) sebesar Rp2.151.479,59/ha dan kubis (musim tanam II) sebesar Rp1.778.758,12/ha.

Jenis dan jumlah pestisida yang digunakan akan disesuaikan dengan hama dan penyakit yang menyerang tanaman pada musim tanam yang bersangkutan. Jenis pestisida yang digunakan dalam usahatani sayuran di Kecamatan Gisting, yaitu Demolish, Akron, Sapporo, Provide-X, Samite, BM Cyclophos, Curacron, Regent, Biocron, Amistartop, Antracol, Magetan, Bion M, Tandem, Gramoxone, dan Rumpas. 
Tabel 1. Rata-rata pendapatan dan R/C usahatani sayuran pola tanam A sawi-cabai-tomat-buncis (musim tanam I) dan kubis (musim tanam II) di Kecamatan Gisting, Kabupaten Tanggamus

\begin{tabular}{|c|c|c|c|c|c|c|}
\hline \multirow[b]{2}{*}{ Uraian } & \multirow[b]{2}{*}{ Satuan } & \multirow[b]{2}{*}{$\begin{array}{c}\text { Harga } \\
(\mathrm{Rp})\end{array}$} & \multicolumn{2}{|c|}{ MT I } & \multicolumn{2}{|c|}{ MT II } \\
\hline & & & Jumlah & $\begin{array}{l}\text { Nilai } \\
\text { (Rp) }\end{array}$ & Jumlah & $\begin{array}{l}\text { Nilai } \\
\text { (Rp) }\end{array}$ \\
\hline 1. Penerimaan & & & & $162.413 .463,21$ & & $74.050 .396,83$ \\
\hline Produksi sawi & $\mathrm{Kg}$ & 814,22 & $26.849,40$ & $21.861 .310,98$ & & \\
\hline Produksi cabai & $\mathrm{Kg}$ & $17.463,32$ & $5.593,45$ & $97.680 .234,03$ & & \\
\hline Produksi tomat & $\mathrm{Kg}$ & $2.359,48$ & $4.123,93$ & $9.730 .340,29$ & & \\
\hline Produksi buncis & $\mathrm{Kg}$ & $4.249,50$ & $7.798,93$ & $33.141 .577,91$ & & \\
\hline Produksi kubis & $\mathrm{Kg}$ & $3.183,33$ & & & $23.261,90$ & $74.050 .396,83$ \\
\hline \multicolumn{7}{|l|}{ 2. Biaya produksi } \\
\hline \multicolumn{7}{|l|}{$\begin{array}{l}\text { I. Biaya tunai: } \\
\text { Biava variabel }\end{array}$} \\
\hline Benih sawi & $\mathrm{Gr}$ & $3.750,00$ & 125,00 & $468.750,00$ & & \\
\hline Benih cabai & $\mathrm{Gr}$ & $12.500,00$ & 111,90 & $1.398 .809,52$ & & \\
\hline Benih tomat & $\mathrm{Gr}$ & $13.500,00$ & 96,43 & $1.301 .785,71$ & & \\
\hline Benih buncis & $\mathrm{Gr}$ & $5.791,67$ & 107,14 & $620.535,71$ & & \\
\hline Benih kubis & $\mathrm{Gr}$ & $6.000,00$ & & & 123,81 & $742.857,14$ \\
\hline \multicolumn{7}{|l|}{ Pupuk: } \\
\hline Pupuk ZA & $\mathrm{Kg}$ & $1.400,00$ & 62,50 & $87.500,00$ & 59,52 & $83.333,33$ \\
\hline Pupuk urea & $\mathrm{Kg}$ & $8.400,00$ & 74,40 & $625.000,00$ & 56,55 & $475.000,00$ \\
\hline Pupuk NPK phonska & $\mathrm{Kg}$ & $2.600,00$ & 68,45 & $177.976,19$ & 65,48 & $170.238,10$ \\
\hline Pupuk TSP & $\mathrm{Kg}$ & $2.100,00$ & 80,36 & $168.750,00$ & 65,48 & $137.500,00$ \\
\hline Pupuk KCl & $\mathrm{Kg}$ & $3.500,00$ & 80,36 & $281.250,00$ & 50,60 & $177.083,33$ \\
\hline Pupuk NPK mutiara & $\mathrm{Kg}$ & $4.371,43$ & 98,21 & $429.336,73$ & 80,36 & $353.936,69$ \\
\hline Pupuk kandang & $\mathrm{Kg}$ & 140,00 & $2.726,19$ & $381.666,67$ & $2.726,19$ & $381.666,67$ \\
\hline Pestisida & $\mathrm{Rp}$ & & & $6.887 .202,38$ & & $2.260 .416,67$ \\
\hline TKLK & HKP & $50.000,00$ & 383,82 & $19.191 .071,43$ & 176,71 & $8.835 .416,67$ \\
\hline Air & $\mathrm{Rp}$ & & & $466.666,67$ & & $214.285,71$ \\
\hline Ajir bambu & $\mathrm{Rp}$ & & & $3.810 .119,05$ & & $3.437 .500,00$ \\
\hline Mulsa & $\mathrm{Rp}$ & & & $3.437 .500,00$ & & \\
\hline Tali rafia & & & & $70.535,71$ & & \\
\hline \multicolumn{7}{|l|}{ Biaya tetap } \\
\hline Sewa lahan & $\mathrm{Rp}$ & & & $535.714,29$ & & $535.714,29$ \\
\hline PBB & $\mathrm{Rp}$ & & & $25.297,62$ & & $25.297,62$ \\
\hline Total biaya tunai & & & & $40.365 .467,69$ & & $17.830 .246,21$ \\
\hline \multicolumn{7}{|l|}{ II. Biaya diperhitungkan } \\
\hline \multicolumn{7}{|l|}{ Biaya variabel } \\
\hline TKDK & HKP & $50.000,00$ & 585,74 & $29.286 .755,95$ & 356,97 & $17.848 .511,90$ \\
\hline \multicolumn{7}{|l|}{ Biaya tetap } \\
\hline Sewa lahan & $\mathrm{Rp}$ & & & $2.500 .000,00$ & & $2.500 .000,00$ \\
\hline Penyusutan alat & $\mathrm{Rp}$ & & & $411.954,37$ & & $411.954,37$ \\
\hline Total biaya diperhitungkan & & & & $32.198 .710,32$ & & $20.760 .466,27$ \\
\hline III. Total biaya & & & & $72.564 .178,00$ & & $38.590 .712,48$ \\
\hline \multicolumn{7}{|l|}{ 3. Pendapatan } \\
\hline I. Pendapatan atas biaya tunai & $\mathrm{Rp}$ & & & 122.047.995,52 & & $56.220 .150,61$ \\
\hline II. Pendapatan atas biaya total & $\mathrm{Rp}$ & & & $89.849 .285,21$ & & $35.459 .684,34$ \\
\hline \multicolumn{7}{|l|}{ 4. R/C Rasio } \\
\hline $\mathrm{R} / \mathrm{C}$ atas biaya tunai & & & & 4,02 & & 4,15 \\
\hline $\mathrm{R} / \mathrm{C}$ atas biaya total & & & & 2,24 & & 1,92 \\
\hline
\end{tabular}

Total biaya yang dikeluarkan untuk pestisida pada tanaman sayuran pola tanam A sawi-cabai-tomatbuncis (musim tanam I) sebesar Rp6.887.202,38/ha dan kubis (musim tanam II) sebesar Rp2.260.516,67/ha. Pada musim tanam pertama, sawi-cabai-tomat-buncis petani mengeluarkan biaya tambahan berupa ajir bambu dan tali rafia, sedangkan pada tanaman kubis tidak terdapat penggunaan ajir bambu dan tali rafia. Pemasangan ajir memiliki fungsi sebagai penopang batang, agar tumbuh ke atas dan tidak jatuh, sedangkan tali rafia berfungsi untuk mengikat batang pohon dengan ajir yang telah dipasang. 
Rata-rata penggunaan tenaga kerja pada usahatani sayuran terbesar, yaitu pada saat persiapan lahan dan panen. Pada kegiatan persiapan lahan, petani responden menyewa mesin traktor secara borongan dengan biaya Rp300.000,00 per 0,25 hektar. Pada kegiatan persiapan lahan selain menyewa traktor sebagai tenaga kerja borongan, petani responden juga membayar upah harian untuk tenaga kerja luar keluarga yang bekerja untuk memasang ajir, membuat guludan, dan memasang mulsa. Pada kegiatan panen, petani responden lebih banyak menggunakan tenaga kerja luar keluarga dengan membayar upah harian, karena kegiatan tersebut memerlukan banyak tenaga kerja agar dapat selesai tepat pada waktunya.

Tabel 1 menunjukkan nilai $\mathrm{R} / \mathrm{C}$ rasio pada musim tanam II lebih besar dibandingkan musim tanam I. Pada musim tanam $\mathrm{I}$, nilai $\mathrm{R} / \mathrm{C}$ rasio yang diperoleh sebesar 4,02 atas biaya tunai dan 2,24 atas biaya total yang memiliki arti bahwa usahatani sayuran yang diusahakan menguntungkan, karena $\mathrm{R} / \mathrm{C}$ rasio lebih besar dari 1,00 . Nilai $\mathrm{R} / \mathrm{C}$ rasio atas biaya tunai sebesar 4,02 berarti bahwa setiap $\mathrm{Rp} 1,00$ biaya tunai yang dikeluarkan petani dapat menghasilkan penerimaan sebesar Rp4,02, sedangkan nilai $\mathrm{R} / \mathrm{C}$ rasio biaya total 2,24 bahwa biaya total yang dikeluarkan petani dapat menghasilkan penerimaan sebesar Rp2,24. Pada musim tanam II nilai $\mathrm{R} / \mathrm{C}$ rasio yang diperoleh sebesar 4,15 atas biaya tunai dan 1,92 atas biaya total yang memiliki arti bahwa usahatani sayuran yang diusahakan menguntungkan, karena $\mathrm{R} / \mathrm{C}$ rasio lebih besar dari 1 . Nilai R/C rasio atas biaya tunai sebesar 4,15 berarti bahwa setiap Rp1,00 biaya tunai yang dikeluarkan petani dapat menghasilkan penerimaan sebesar Rp4,15, sedangkan nilai R/C rasio biaya total 1,92 bahwa biaya total yang dikeluarkan petani dapat menghasilkan penerimaan sebesar Rp1,92.

b. Pola tanam B sawi-cabai-tomat (musim tanam I) dan kubis (musim tanam II)

Petani menggunakan benih sesuai dengan pengalaman berusahatani. Harga benih yang dibeli petani dari kios pertanian relatif sama, karena petani responden membeli benih di tempat yang sama yang ada di Kecamatan Gisting.

Jenis pupuk kimia yang sering digunakan oleh petani di lokasi penelitian adalah pupuk ZA, urea, NPK phonska, TSP, $\mathrm{KCl}$, dan NPK mutiara. Penggunaan pupuk kimia tidak sesuai anjuran yang ditetapkan oleh Pusat Penelitian dan Pengembangan Hortikultura (2017), karena penggunaan pupuk lebih sedikit dibandingkan anjuran yang telah ditetapkan. Penggunaan ratarata pupuk kandang masih sedikit yaitu 2.806,27 $\mathrm{kg} / \mathrm{ha} /$ musim tanam di bawah standar dosis dari Pusat Penelitian dan Pengembangan Hortikultura yaitu sebesar $30.000,00 \mathrm{~kg} / \mathrm{ha}$. Total biaya yang dikeluarkan untuk pupuk pada tanaman sayuran pola tanam A sawi-cabai-tomat (musim tanam I) sebesar Rp2.042.450,14/ha dan kubis (musim tanam II) sebesar Rp1.804.065,31/ha.

Jenis dan jumlah pestisida yang digunakan akan disesuaikan dengan hama dan penyakit yang menyerang tanaman pada musim tanam yang bersangkutan. Jenis pestisida yang digunakan dalam usahatani sayuran di Kecamatan Gisting, yaitu Demolish, Akron, Sapporo, Provide-X, Samite, BM Cyclophos, Curacron, Regent, Biocron, Amistartop, Antracol, Magetan, Bion M, Tandem, Gramoxone, dan Rumpas. Total biaya yang dikeluarkan untuk pestisida pada tanaman sayuran pola tanam A sawi-cabai-tomat-buncis (musim tanam I) sebesar Rp6.357.549,86/ha dan kubis (musim tanam II) sebesar Rp2.485.042,74/ha.

Pada musim tanam pertama sawi-cabai-tomat petani mengeluarkan biaya tambahan berupa ajir bambu dan tali rafia, sedangkan pada tanaman kubis tidak terdapat penggunaan ajir bambu dan tali rafia. Pemasangan ajir memiliki fungsi sebagai penopang batang, agar tumbuh ke atas dan tidak jatuh, sedangkan tali rafia berfungsi untuk mengikat batang pohon dengan ajir yang telah dipasang.

Rata-rata penggunaan tenaga kerja pada usahatani sayuran terbesar, yaitu pada saat persiapan lahan dan panen. Pada kegiatan persiapan lahan, petani responden menyewa mesin traktor secara borongan dengan biaya Rp300.000,00 per 0,25 hektar. Pada kegiatan persiapan lahan selain menyewa traktor sebagai tenaga kerja borongan, petani responden juga membayar upah harian untuk tenaga kerja luar keluarga yang bekerja untuk memasang ajir, membuat guludan, dan memasang mulsa. Pada kegiatan panen, petani responden lebih banyak menggunakan tenaga kerja luar keluarga dengan membayar upah harian, karena kegiatan tersebut memerlukan banyak tenaga kerja agar dapat selesai tepat pada waktunya.

Data pada Tabel 2 menunjukkan nilai $\mathrm{R} / \mathrm{C}$ rasio pada musim tanam I lebih besar dibandingkan musim tanam II. 
Tabel 2. Rata-rata pendapatan dan R/C usahatani sayuran pola tanam B sawi-cabai-tomat (musim tanam I) dan kubis (musim tanam II) di Kecamatan Gisting, Kabupaten Tanggamus

\begin{tabular}{|c|c|c|c|c|c|c|}
\hline \multirow[b]{2}{*}{ Uraian } & \multirow[b]{2}{*}{ Satuan } & \multirow[b]{2}{*}{$\begin{array}{c}\text { Harga } \\
\text { (Rp) }\end{array}$} & \multicolumn{2}{|c|}{ MT I } & \multicolumn{2}{|c|}{ MT II } \\
\hline & & & Jumlah & $\begin{array}{l}\text { Nilai } \\
\text { (Rp) }\end{array}$ & Jumlah & $\begin{array}{l}\text { Nilai } \\
\text { (Rp) }\end{array}$ \\
\hline 1. Penerimaan & & & & $152.212 .771,62$ & & $68.089 .004,96$ \\
\hline Produksi sawi & $\mathrm{Kg}$ & 822,87 & $27.792,74$ & $22.869 .777,33$ & & \\
\hline Produksi cabai & $\mathrm{Kg}$ & $17.488,72$ & $6.529,91$ & $114.199 .830,89$ & & \\
\hline Produksi tomat & $\mathrm{Kg}$ & $2.318,44$ & $6.531,62$ & $15.143 .163,39$ & & \\
\hline Produksi kubis & $\mathrm{Kg}$ & $3.185,19$ & & & $21.376,78$ & $68.089 .004,96$ \\
\hline \multicolumn{7}{|l|}{ 2. Biaya produksi } \\
\hline \multicolumn{7}{|l|}{ I. Biaya tunai: } \\
\hline Benih sawi & $\mathrm{Gr}$ & $3.740,74$ & 111,11 & $415.637,86$ & & \\
\hline Benih cabai & $\mathrm{Gr}$ & $12.500,00$ & 119,66 & $1.495 .726,50$ & & \\
\hline Benih tomat & $\mathrm{Gr}$ & $13.500,00$ & 113,96 & $1.538 .461,54$ & & \\
\hline Benih kubis & $\mathrm{Gr}$ & $6.000,00$ & & & 118,23 & $709.401,71$ \\
\hline \multicolumn{7}{|l|}{ Pupuk: } \\
\hline Pupuk ZA & $\mathrm{Kg}$ & $1.400,00$ & 60,54 & $84.757,83$ & 64,10 & $89.743,59$ \\
\hline Pupuk urea & $\mathrm{Kg}$ & $8.400,00$ & 85,47 & $717.948,72$ & 71,23 & $598.290,60$ \\
\hline Pupuk NPK phonska & $\mathrm{Kg}$ & $2.600,00$ & 67,66 & $175.925,93$ & 46,30 & $120.370,37$ \\
\hline Pupuk TSP & $\mathrm{Kg}$ & $2.100,00$ & 64,10 & $134.615,38$ & 35,61 & $74.786,32$ \\
\hline Pupuk KCl & $\mathrm{Kg}$ & $3.500,00$ & 64,10 & $224.358,97$ & 78,35 & $274.216,52$ \\
\hline Pupuk NPK mutiara & $\mathrm{Kg}$ & $4.380,00$ & 71,23 & $311.965,81$ & 56,98 & $253.780,41$ \\
\hline Pupuk kandang & $\mathrm{Kg}$ & 140,00 & $2.806,27$ & $392.877,49$ & $2.806,27$ & $392.877,49$ \\
\hline Pestisida & $\mathrm{Rp}$ & & & $6.357 .549,86$ & & $2.485 .042,74$ \\
\hline TKLK & HKP & $50.000,00$ & 492,85 & $24.642 .450,14$ & 221,36 & $11.068 .019,94$ \\
\hline Air & $\mathrm{Rp}$ & & & $549.857,55$ & & $247.863,25$ \\
\hline Ajir bambu & $\mathrm{Rp}$ & & & $3.497 .863,25$ & & 0,00 \\
\hline Mulsa & $\mathrm{Rp}$ & & & $3.525 .641,03$ & & $3.525 .641,03$ \\
\hline Tali rafia & $\mathrm{Rp}$ & & & $85.398,86$ & & 0,00 \\
\hline \multicolumn{7}{|l|}{ Biaya tetap } \\
\hline Sewa lahan & $\mathrm{Rp}$ & & & 0,00 & & 0,00 \\
\hline PBB & $\mathrm{Rp}$ & & & $25.106,84$ & & $25.106,84$ \\
\hline Total biaya tunai & & & & $44.176 .143,56$ & & $19.865 .140,81$ \\
\hline \multicolumn{7}{|l|}{ II. Biaya diperhitungkan } \\
\hline \multicolumn{7}{|l|}{ Biaya variabel } \\
\hline TKDK & HKP & $50.000,00$ & 899,05 & $44.952 .635,33$ & 518,00 & $25.899 .928,77$ \\
\hline \multicolumn{7}{|l|}{ Biaya tetap } \\
\hline Sewa lahan & $\mathrm{Rp}$ & & & $3.012 .820,51$ & & $3.012 .820,51$ \\
\hline Penyusutan alat & $\mathrm{Rp}$ & & & $516.536,09$ & & $516.536,09$ \\
\hline Total biaya diperhitungkan & & & & 48.481.991,93 & & $29.429 .285,38$ \\
\hline III. Total biaya & & & & $92.658 .135,49$ & & $49.294 .426,18$ \\
\hline \multicolumn{7}{|l|}{ 3. Pendapatan } \\
\hline I. Pendapatan atas biaya tunai & $\mathrm{Rp}$ & & & $108.036 .628,06$ & & $48.223 .864,15$ \\
\hline II. Pendapatan atas biaya total & $\mathrm{Rp}$ & & & $59.554 .636,13$ & & $18.794 .578,78$ \\
\hline \multicolumn{7}{|l|}{ 4. $\mathrm{R} / \mathrm{C}$ rasio } \\
\hline $\mathrm{R} / \mathrm{C}$ atas biaya tunai & & & & 3,45 & & 3,43 \\
\hline $\mathrm{R} / \mathrm{C}$ atas biaya total & & & & 1,64 & & 1,38 \\
\hline
\end{tabular}

Tabel 3. Rata-rata pendapatan rumah tangga petani sayuran di Kecamatan Gisting, Kabupaten Tanggamus

\begin{tabular}{lrrrr}
\hline \multirow{2}{*}{ Sumber pendapatan } & \multicolumn{2}{c}{ Pola tanam A } & \multicolumn{2}{c}{ Pola tanam B } \\
\cline { 2 - 5 } & $\begin{array}{c}\text { Rata-rata pendapatan } \\
\text { (Rp/tahun) }\end{array}$ & $\begin{array}{c}\text { Persentase } \\
(\%)\end{array}$ & $\begin{array}{c}\text { Rata-rata pendapatan } \\
\text { (Rp/tahun) }\end{array}$ & $\begin{array}{r}\text { Persentase } \\
(\%)\end{array}$ \\
\hline Pendapatan on farm & $64.381 .351,15$ & 90,16 & $44.270 .320,57$ & 88,93 \\
Pendapatan off farm & $4.379 .166,67$ & 6,13 & $4.185 .185,19$ & 8,41 \\
Pendapatan non farm & $2.650 .000,00$ & 3,71 & $1.325 .925,93$ & 2,66 \\
\hline Jumlah & $71.410 .517,81$ & 100,00 & $49.781 .431,68$ & 100,00 \\
\hline
\end{tabular}


Pada musim tanam I nilai $\mathrm{R} / \mathrm{C}$ rasio yang diperoleh sebesar 3,45 atas biaya tunai dan 1,64 atas biaya total yang memiliki arti bahwa usahatani sayuran yang diusahakan menguntungkan, karena $\mathrm{R} / \mathrm{C}$ rasio lebih besar dari 1 . Nilai $\mathrm{R} / \mathrm{C}$ rasio atas biaya tunai sebesar 3,45 berarti bahwa setiap Rp1,00 biaya tunai yang dikeluarkan petani dapat menghasilkan penerimaan sebesar Rp3,45, sedangkan nilai R/C rasio biaya total 1,64 bahwa biaya total yang dikeluarkan petani dapat menghasilkan penerimaan sebesar Rp1,64. Pada musim tanam II nilai R/C rasio yang diperoleh sebesar 3,43 atas biaya tunai dan 1,38 atas biaya total yang memiliki arti bahwa usahatani sayuran yang diusahakan menguntungkan, karena $\mathrm{R} / \mathrm{C}$ rasio lebih besar dari 1. Nilai $\mathrm{R} / \mathrm{C}$ rasio atas biaya tunai sebesar 3,43 berarti bahwa setiap Rp1,00 biaya tunai yang dikeluarkan petani dapat menghasilkan penerimaan sebesar Rp3,43, sedangkan nilai $\mathrm{R} / \mathrm{C}$ rasio biaya total 1,38 bahwa biaya total yang dikeluarkan petani dapat menghasilkan penerimaan sebesar Rp1,38.

Hasil penelitan ini sejalan dengan Penelitian Heriani, Zakaria dan Soelaiman (2013) tentang usahatani tomat yang menyebutkan bahwa usahatani tersebut layak untuk diusahakan, karena $\mathrm{R} / \mathrm{C}>1$. Sama halnya dengan penelitian Nopiana dan Siti (2011), yang menunjukkan bahwa semua pola tanam yang diteliti pada daerah penelitian menguntungkan. Rata-rata pendapatan usahatani pada penelitian ini tergolong tinggi dibandingkan Penelitian Heriani et al (2013), yaitu sebesar Rp11.030.913,25. Selain itu, penelitian ini juga sejalan dengan Penelitian Adityas, Hasyim dan Affandi (2018) tentang usahatani sayuran juga menyebutkan bahwa usahatani tersebut layak untuk diusahakan dengan nilai $\mathrm{R} / \mathrm{C}>1$. Perbedaan tersebut disebabkan oleh lokasi dan kondisi pertanian yang berbeda.

\section{Pendapatan Rumah Tangga}

Pendapatan rumah tangga dalam penelitian ini diperoleh dengan menjumlahkan seluruh pendapatan yang berasal dari usahatani sayuran, usahatani bukan sayuran (non farm), pendapatan yang berasal dari luar budidaya (off farm) serta pendapatan yang berasal dari non pertanian (non farm) yang disajikan pada Tabel 3. Data pada Tabel 3 menunjukkan bahwa pendapatan on farm menjadi kontribusi terbesar penyokong pendapatan rumah tangga petani responden. Hal itu karena kegiatan on farm, terutama usahatani sayuran merupakan sumber pendapatan utama untuk semua responden. Tingginya kontribusi sektor pertanian terhadap total pendapatan rumah tangga sejalan dengan Penelitian Permadi, Widjaya dan Kalsum (2016) bahwa sektor pertanian memegang peranan penting dalam penyerapan tenaga kerja maupun kontribusinya sebagai penyumbang pendapatan.

Berdasarkan penggolongan pendapatan menurut Bank Dunia, garis kemiskinan internasional sebesar 1 dollar Amerika Serikat per kapita per hari, sehingga dapat disimpulkan bahwa pendapatan rumah tangga petani sayuran di Kecamatan Gisting Kabupaten Tanggamus termasuk ke dalam rumah tangga sejahtera. Hal itu disebabkan jika dilakukan perhitungan pendapatan per kapita per hari, maka pendapatan rata-rata rumah tangga petani sayuran pola tanam A sebesar Rp65.215,08 per kapita per hari, sedangkan petani pola tanam B sebesar Rp34.096,87 per kapita per hari.

\section{Analisis Tingkat Kesejahteraan Rumah Tangga Petani Sayuran Berdasarkan Kriteria BPS (2014)}

Kriteria Badan Pusat Statistik (2014) digunakan untuk mengukur tingkat kesejahteraan petani di lokasi penelitian. Pendekatan-pendekatan yang dilakukan terhadap indikator, yaitu kependudukan, kesehatan dan gizi, pendidikan, ketenagakerjaan, pola konsumsi, perumahan dan lingkungan serta sosial dan lain-lain. Rekapitulasi perolehan berdasarkan skor tujuh indikator tingkat kesejahteraan menurut Badan Pusat Statistik dapat dilihat pada Tabel 4.

Hasil penelitian menunjukkan bahwa 82,35 persen petani responden yang masuk kategori sejahtera, selebihnya berada pada kategori tidak sejahtera. Salah satu faktor yang menyebabkan hal tersebut terletak pada indikator ketenagakerjaan. Terdapat 9 keluarga yang tergolong belum sejahtera tersebut, ada yang tidak memiliki pekerjaan tambahan selain berusahatani dan merasa upah yang diterima belum sesuai harapan, sehingga menjadi penyebab rendahnya pendapatan yang diterima.

Tabel 4. Tingkat kesejahteraan rumah tangga petani sayuran di Kecamatan Gisting, Kabupaten tanggamus

\begin{tabular}{lcrr}
\hline \multicolumn{1}{c}{ Kategori } & $\begin{array}{c}\text { Kelas } \\
\text { interval }\end{array}$ & $\begin{array}{r}\text { Jumlah } \\
\text { (orang) }\end{array}$ & $\begin{array}{r}\text { Persentase } \\
(\%)\end{array}$ \\
\hline Sejahtera & $15-21$ & 42 & 82,35 \\
Belum sejahtera & $07-14$ & 9 & 17,65 \\
\hline Jumlah & & 51 & 100,00 \\
\hline
\end{tabular}




\section{KESIMPULAN}

Usahatani pola tanam A sawi-cabai-tomat-buncis (musim tanam I) kubis (musim tanam II), dan pola tanam B sawi-cabai-tomat (musim tanam I) kubis (musim tanam II) menguntungkan untuk diusahakan $(\mathrm{R} / \mathrm{C}>1)$. Pendapatan rumah tangga petani dari pendapatan on farm memberikan kontribusi tertinggi, pendapatan rumah tangga yang diterima petani pola tanam A sebesar Rp71.410.517,81/tahun, sedangkan pola tanam B sebesar Rp49.781.431,68/tahun. Berdasarkan kriteria Badan Pusat Statistik (2014), terdapat 82,35 persen rumah tangga petani sayuran di Kecamatan Gisting Kabupaten Tanggamus yang tergolong ke dalam rumah tangga sejahtera.

\section{DAFTAR PUSTAKA}

Adityas MR, Hasyim AI dan Affandi MI. 2018. Analisis pendapatan usahatani dan pemasaran sayuran unggulan di Kawasan Agropolitan Kabupaten Tanggamus. JIIA, 6 (1): 41-48. http://jurnal.fp.unila.ac.id/index. php/JIA/article/view/2497/2181 September 2018]

BPS [Badan Pusat Statistik]. 2014. Indikator Kesejahteraan Rakyat 2007. Badan Pusat Statistik. Jakarta.

BPS [Badan Pusat Statistik]. 2017. Keadaan Ketenagakerjaan Februari 2017. http://www.bps.go.id/brs_file/naker_06mei 17.pdf. [18 Desember 2017].

BPS [Badan Pusat Statistik]. 2018. Definisi Tenaga Kerja. $\quad$ http://bps.go.id/subject/6/tenaga kerja.html. [17 Desember 2018].

Direktorat Jendral Holtikultura. 2015. Statistik Produksi Hortikultura Tahun 2014. Kementerian Pertanian. Jakarta.

Dinas Pengendalian Penduduk dan Keluarga Berencana Kabupaten Tanggamus. 2017. Jumlah Keluarga Menurut Kecamatan Dan Klasifikasi Keluarga di Kabupaten Tanggamus Tahun 2017. Dinas Pengendalian Penduduk dan Keluarga Berencana Kabupaten Tanggamus. Kotaagung.
Hastuti DHD dan Rahim ABD. 2008. Pengantar, Teori, dan Kasus Ekonomi Pertanian. Penebar Swadaya. Jakarta.

Heriani N, Zakaria WA dan Soelaiman A. 2013. Analisis keuntungan dan risiko usahatani tomat di Kecamatan Sumberejo Kabupaten Tanggamus. JIIA, 1 (2): 169-173. http://jurnal.fp.unila.ac.id/index.php/JIA/arti cle/view/244/243 [17 Desember 2018]

Nopiana S dan Siti B. 2011. Analisis pendapatan pola tanam beruntun tanaman hortikultura di Desa Bangunrejo Kecamatan Tenggarong Seberang Kabupaten Kutai. Jurnal EPP, 8 (1):30-40. http//agribisnisfpumjurnal.files. wordpress.com/2012/03/jurnal-vol-8-no-1 sinta.pdf [11 Januari 2019].

Pusat Penelitian dan Pengembangan Hortikultura. 2017. Teknologi produksi sayuran sawi. http://jakarta.litbang.pertanian.go.id/ind/ind ex.php/publikasi/liptan/69-teknologiproduksi-sayuran-sawi [15 Februari 2019].

Permadi YB, Widjaya S dan Kalsum U. 2016. Distribusi pendapatan rumah tangga dan kesejahteraan petani sayur di Desa Simpang Kanan Kecamatan Sumberejo Kabupaten Tanggamus. JIIA, 4 (2): 145-151. http://jurnal.fp.unila.ac.id/index.php/JIA/art icle/view/1231/1128. [18 Desember 2017].

Soekartawi. 1995. Analisis Usahatani. Rajawali Press. Jakarta.

Soekartawi. 2002. Analisis Usahatani. UI-Press. Jakarta.

Sugiarto D, Siagian LS, Sunaryanto dan Oetomo DS. 2003. Teknik Sampling. Gramedia. Jakarta. 